\title{
Step-by-Step Transition from Clay to Soil Shrinkage Curve
}

\author{
V.Y. Chertkov*
}

Agricultural Engineering Division, Faculty of Civil and Environmental Engineering, Technion, Haifa 32000, Israel

\begin{abstract}
Clay and soil containing it have shrinkage curves that are qualitatively different in shape. The objective of this work is to qualitatively show with maximum simplicity, how a clay shrinkage curve turns into a soil shrinkage curve. Because of the crack volume the measured shrinkage curve is not the single-valued feature of a soil. We use a concept of the reference shrinkage curve that is only stipulated by soil shrinkage without cracking, single-valued, and qualitatively similar to an observed shrinkage curve. We also use new concepts of an intra-aggregate soil structure: (i) a deformable, but non-shrinking surface layer of aggregates that loses water during shrinkage; and (ii) lacunar pores (micro-cracks) inside an intra-aggregate clay that increase in volume during shrinkage. Then, through a series of consecutive steps, illustrating each step by a separate graphic presentation, we move from a clay shrinkage curve to a soil shrinkage curve with predicted qualitative features that coincide with those experimentally observed in numerous soil shrinkage publications. We thereby demonstrate the qualitative physical impact of the intra-aggregate structure on soil shrinkage.
\end{abstract}

Keywords: Clay, soil, reference shrinkage, lacunar pores, aggregate surface layer.

\section{INTRODUCTION}

The shrinkage curves of a soil (e.g., $[1,2])$ and the clay contributing to it (e.g., [3]) are qualitatively different (Fig. 1) even if the organic matter content is negligible and the clay is the only shrink-swell component of the soil. These differences were recently quantitatively explained at any clay content [4-6]. The qualitative differences between the shape of clay and aggregated soil shrinkage curves are as follows [4]:

(a) unlike pure clays (Fig. 1a), in the main part of the structural shrinkage area $\left(W_{\mathrm{s}}<W<W_{\mathrm{h}}\right.$; Fig. (1b)) the soil shrinkage curve is convex upward;

(b) unlike pure clays (Fig. 1a), the slope of the soil shrinkage curve in the structural shrinkage area is essentially less than unity and, in general, varies with water content; the shrinkage curve can even have an inflection point in the area (see Fig. (1b), curves 1 and 2) (e.g., [2]);

(c) in the basic shrinkage area $\left(W_{\mathrm{n}}<W<W_{\mathrm{s}}\right.$; Fig. 1b) the shrinkage curve slope is constant for a given soil, but unlike the different clays (when the slope is always equal to unity; Fig. (1a)) for different soils the slope varies between zero and unity; and

(d) unlike pure clays, the maximum swelling point, $W_{\mathrm{h}}$ (or the shrinkage start point) of a soil can be situated at the pseudo saturation line (Fig. 1b) (e.g., [2]).

In general, the shrinkage curve of an aggregated soil is non-single valued because the volume of (macro) cracks between primary aggregates depends on sampling, sample preparation, sample size, and drying regime [7-12]. How-

*Address correspondence to this author at the Division of Environmental, Water and Agricultural Engineering, Faculty of Civil \& Environmental Engineering, Technion, Haifa 32000, Israel; Tel: 972-4 - 829-2499; Fax: 972-4-8295696; E-mail: agvictor@tx.technion.ac.il ever, the qualitative view of the shrinkage curve in Fig. (1b) is kept at any inter-aggregate cracking. For this reason, to
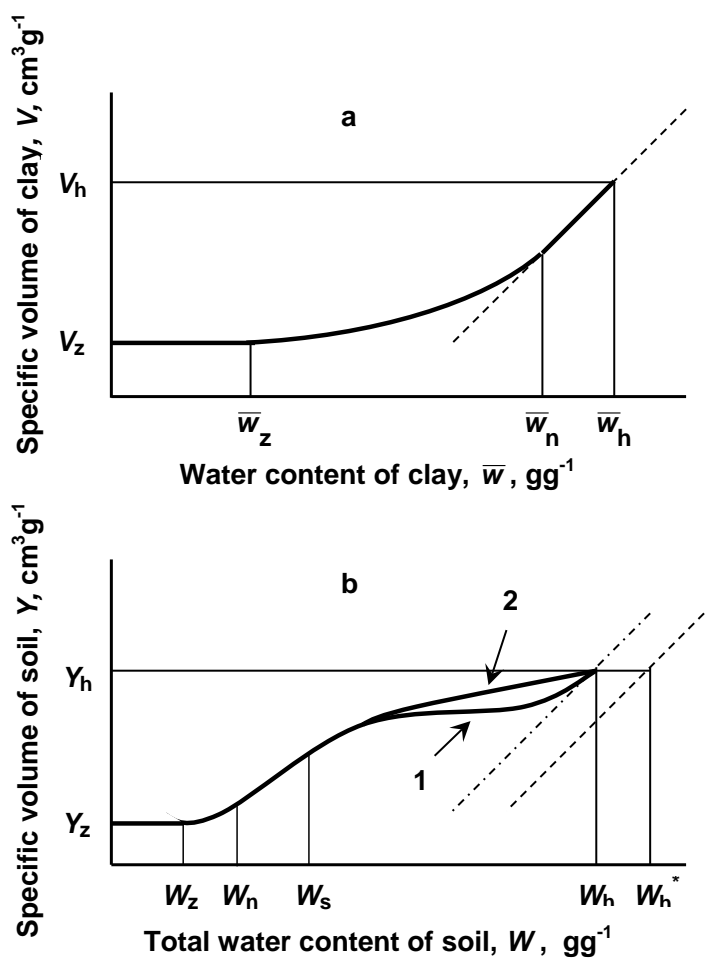

Fig. (1). Qualitative view of (a) the clay and (b) soil shrinkage curves (modified Fig. (1) from [4]). Subscripts "z", "n", "s" and " $h$ " correspond to the shrinkage limit, air-entry point, final point of structural shrinkage, and maximum swelling point, respectively. The curve slope in the basic shrinkage area for clay is always unity, but for soil it can also be less than unity. Curves 1 and 2 are the observed variants in the structural shrinkage area. Dashed and dash-dot lines are the true and pseudo saturation lines, respectively. $\left(W_{\mathrm{h}}{ }^{*}-W_{\mathrm{h}}\right) / \rho_{\mathrm{w}}$ gives the volume of non-connected isolated pores that remain non-water filled. 
consider the effects of soil structure on shrinkage curve, Chertkov [4-6] used the reference shrinkage curve that by definition only corresponds to soil clay shrinkage without inter-aggregate cracking and can be predicted in a single valued manner. The negligible volume of inter-aggregate cracks suggests sufficiently small samples and an approximately constant volume of structural (inter-aggregate) pores whose deformation initiates the development of interaggregate cracks.

The reference shrinkage curve can be interesting for numerous applications, and first of all for estimating the crack volume contribution to a measured shrinkage curve. In addition, since the reference shrinkage curve differs from the observed shrinkage curve quantitatively, but not qualitatively, it can also be used to reach fundamental understanding of the origin of the abovementioned differences between the shrinkage curves in Fig. (1a) and Fig. (1b).

All the current models of the soil shrinkage curve, at all the differences between them, are based on the approximation of the experimental shrinkage curve data by some a priori taken mathematical expression (different for each different approach) $[10,11,13-20]$. Such expressions are not derived from considerations of the soil inter- and intraaggregate structure, but justified by the fitting of their parameters (from 3 to 11 depending on the approach) to the experimental shrinkage curve data. The a priori accepted mathematical approximation of a shrinkage curve can be useful for applications (e.g., [19, 20]) and other aims (e.g., [18]). However, explanation and understanding of the characteristic features (see above (a) through (d)) of a soil shrinkage curve and their origin, implies qualitative or quantitative derivation of the shrinkage curve from inter- and intra-aggregate soil structure. Accepting some empirical approximation for the shrinkage curve from the beginning (in the frame of existing models) obviously makes such a deri-

a

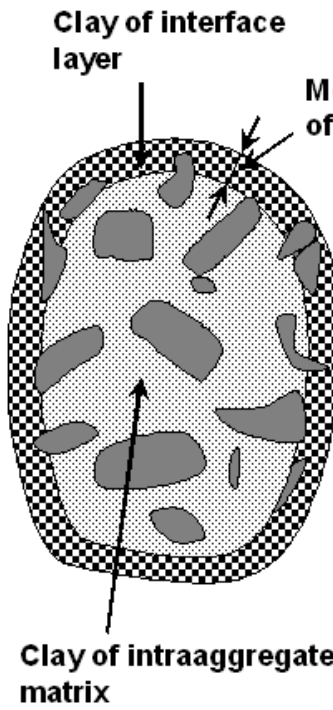

vation meaningless because one can only obtain the approximation that has been a priori given.

Chertkov [4-6] relied on the new concepts (and, correspondingly, assumptions) of intra-aggregate soil structure. These concepts were in part inspired by observations from [21]. In general, in addition to the structural pores (associated with inter-aggregate space) and clay pores (associated with the space between clay particles), the soils also contain the micro-cracks or lacunar pores inside a clay of primary aggregates [21]. These researches observed lacunar pores (Fig. 2) in clay matrices entering the oven-dried artificial clay-silt-sand mixtures. At sufficiently small clay content, $c$ the lacunar pores are three-dimensional, have an appreciable volume (up to that of inter-grain space), and form a network. By increasing the clay content the lacunar pore network gradually disappears, and only isolated (hidden) lacunar pores remain. At sufficiently high clay content the lacunar pores have a crack-like shape and negligible volume.

The consideration of the reference shrinkage curve was based on three assumptions [4].

\section{Assumption 1}

At a given clay type and porosity $p$ of silt and sand grains coming into contact, there is such a critical clay content, $c^{*}$ that at a soil clay content $c>c{ }^{*}$ lacunar pores inside clay and grain contacts are lacking (Fig. 2a), but at a soil clay content $c<c^{*}$ lacunar pores exist and grain contacts can exist at sufficiently small water contents (Fig. $\mathbf{2 b}$ and $\mathbf{2 c}$ ). If $c<\mathrm{c}^{*}$ and the lacunar pores exist (Fig. 2b and 2c) they can reach the sizes of inter-grain spaces and are usually large compared to clay pores and emptied (if water-filled) before them. Observations [21] show that $c^{*}$ can be between $\sim 0.3$ and $\sim 0.8$, but a typical value $c^{*} \cong 0.4$ [22]. The critical value $c^{*}$ to be defined by the above assumption is expressed through porosity $p$, the b

Aggregate

Mean thickness of interface layer
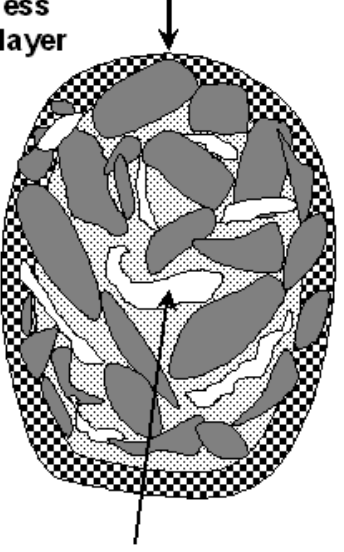

Lacunar pore
C

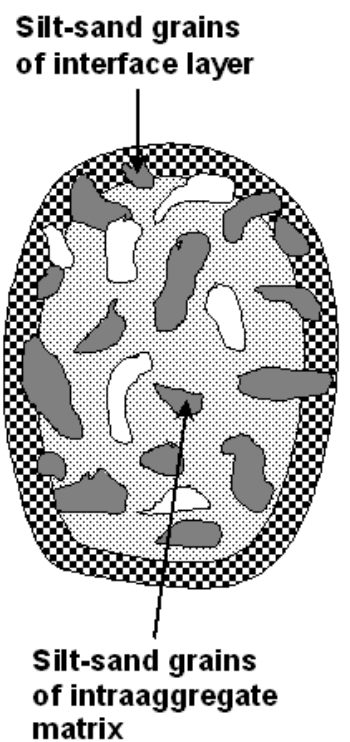

Fig. (2). The illustrative scheme of the internal structure of aggregates at a clay content: (a) $c>c^{*}$, without lacunar pores; (b) $c<c^{*}$, with lacunar pores and silt-sand grain contacts at $w=0$; and (c) $c<c^{*}$, with lacunar pores and non-totally contacting silt-sand grains at any water content (Fig. (2) from [6]). 
relative volume of the clay solids, $v_{\mathrm{s}}$, and the relative ovendried clay volume, $v_{\mathrm{z}}$ (the $v_{\mathrm{S}}$ and $v_{\mathrm{z}}$ values are connected with clay type, see $[23,24])$ and is in agreement with data from [21].

\section{Assumption 2}

The shrinkage of an intraaggregate clay, aggregates, and soil, as a whole, starts simultaneously at total soil water content, $W_{\mathrm{h}}$ corresponding to the point of maximum soil swelling or point of shrinkage start (Fig. 1b).

\section{Assumption 3}

Water in the clay pores of a deformable, but nonshrinking surface layer of aggregates (Fig. 2) with modified pore structure (interface layer) and the layer volume, determine a soil reference shrinkage curve in the structural shrinkage area.

The quantitative consideration from [4-6] is quite complex. At the same time, based on the above concepts and assumptions, one can propose the relatively simple qualitative explanation of the above shape features of the soil reference shrinkage curve originating from those of the clay shrinkage curve. Thus, unlike the quantitative consideration from [4-6] that was conducted using a number of inevitable complications, the objective of this work is to show that a simple qualitative physical explanation and understanding of the transformation of a clay shrinkage curve (Fig. 1a) to the reference shrinkage curve of a soil (Fig. 1b) with any clay content and with the above characteristic features from (a) to (d), can be reached without any calculations and only using rather simple means. In addition, our aim is to illustrate the approach with maximum possible simplicity and clearness, step by step, using a separate graphic presentation for each step (unlike [4-6] where the steps are shown together, in one complex figure).

Correspondingly, the data that we are going to use for comparison with theoretical results, relate to the qualitative aspects of the shrinkage curve shape. The qualitative aspects were formulated above as characteristic features from (a) to (d) [4-6] and visually shown in Fig. (1). As for the experimental observations of these qualitative aspects, the reader can turn to numerous soil shrinkage publications, major of which have already been mentioned above. Notation is summarized at the end of the paper.

\section{THE SHRINKAGE CURVE OF A PURE CLAY $(V(\bar{w}))$}

We start from a disaggregated clay. The shrinkage curve of a disaggregated clay can be written as

$V(\bar{w})=1 / \rho_{\mathrm{s}}+V_{\mathrm{cp}}(\bar{w})$

where $V$ is the specific volume of the clay; $\bar{w}$ - the gravimetric water content of the clay; $\rho_{\mathrm{s}}$ - the density of solids (clay particles); and $V_{\mathrm{cp}}$ - the specific volume of the clay (matrix) pores. In the frames of the model [23, 24] Eq. (1) gives (see Fig. (1a), solid line shows a qualitative view of $V(\bar{w}))$

$$
V(\bar{w})= \begin{cases}V_{\mathrm{z}} \equiv 1 / \rho_{\mathrm{s}} & 0 \leq \bar{w} \leq \bar{w}_{\mathrm{z}} \\ +V_{\mathrm{cp}}\left(\bar{w}_{\mathrm{z}}\right), & \\ V_{\mathrm{z}}+a\left(\bar{w}-\bar{w}_{\mathrm{z}}\right)^{2}, & \bar{w}_{\mathrm{z}} \leq \bar{w} \leq \bar{w}_{\mathrm{n}} \\ 1 / \rho_{\mathrm{s}}+\bar{w} / \rho_{\mathrm{w}}, & \bar{w}_{\mathrm{n}} \leq \bar{w} \leq \bar{w}_{\mathrm{M}}\end{cases}
$$

where $\bar{w}_{\mathrm{z}}, \bar{w}_{\mathrm{n}}$, and $\bar{w}_{\mathrm{M}}$ are the clay shrinkage limit, airentry point, and the liquid limit, respectively (at natural swelling only the maximum swelling point, $\bar{w}_{\mathrm{h}}<\bar{w}_{\mathrm{M}}$ is reached); $\rho_{\mathrm{w}}$ - the water density; and $a$ - a coefficient depending on $V_{\mathrm{z}}, \bar{w}_{\mathrm{M}}$, and $\rho_{\mathrm{s}}[23,24]$.

\section{THE SHRINKAGE CURVE OF AN INTRA- AGGREGATE MATRIX $(U(w))$}

The aim of this section is to show the link between the shrinkage curve of an intra-aggregate matrix (Fig. 2) and the above shrinkage curve of a clay that contributes to it.

\subsection{Lacunar Pore Volume $\left(U_{\mathrm{lp}}(w)\right)$ and Lacunar Factor (k)}

The specific volume $U(w)$ of the intra-aggregate matrix (Fig. 2a, 2b, and 2c) where $w$ is the gravimetric water content of the matrix, includes the constant specific volume $1 / \rho_{\mathrm{s}}$ of solids as well as the specific volumes of lacunar pores $U_{\mathrm{lp}}$ and clay pores $U_{\mathrm{cp}}$ as (note that here we rely on the assumptions from Section 1)

$U(w)=1 / \rho_{\mathrm{s}}+U_{\mathrm{lp}}(w)+U_{\mathrm{cp}}(w), 0 \leq w \leq w_{\mathrm{h}}$

where $w_{\mathrm{h}}$ is the maximum swelling point of the intraaggregate matrix at natural swelling $\left(w_{\mathrm{h}}<w_{\mathrm{M}}\right.$ where $w_{\mathrm{M}}$ is the liquid limit of the intra-aggregate matrix). In Eqs. (2) and (3) for the sake of simplicity we do not take into account a possible small difference between the density of silt-sand grains and clay solids, and correspondingly, the difference between the clay content by weight and the volume fraction of clay solids. The corresponding modification is possible but introduces a superfluous complication.

The small variation $\mathrm{d} U_{\mathrm{cp}}$ of the clay pore volume at shrinkage $\left(\mathrm{d} U_{\mathrm{cp}}<0\right)$, corresponding to a water loss $\mathrm{d} w<0$, initiates both the variation $\mathrm{d} U$ of the intra-aggregate matrix volume $(\mathrm{d} U<0)$ and the variation $\mathrm{d} U_{\mathrm{lp}}$ of the lacunar pore volume $\left(\mathrm{d} U_{\mathrm{lp}}>0\right.$ since the shrinkage of intra-aggregate clay leads to the lacunar pore volume increase). According to Eq. (3) the obvious volume balance takes place as

$\mathrm{d} U_{\mathrm{cp}}=\mathrm{d} U-\mathrm{d} U_{\mathrm{lp}}, 0 \leq w \leq w_{\mathrm{h}}$.

Based on the balance relation one can present $\mathrm{d} U_{\mathrm{lp}}$ and $\mathrm{d} U$ as

$\mathrm{d} U_{\mathrm{lp}}=-k \mathrm{~d} U_{\mathrm{cp}}, 0 \leq w \leq w_{\mathrm{h}}$

$\mathrm{d} U=(1-k) \mathrm{d} U_{\mathrm{cp}}, 0 \leq w \leq w_{\mathrm{h}}$. 
In general, in Eqs. (5) and (6) the lacunar factor, $k$ is a function of clay and water content, $k(c, w)$ with values varying in the range $0 \leq k \leq 1$. At a high clay content $\left(c>c^{*}\right)$ the lacunar pore volume is negligible (Fig. 2a) and according to Eq. (5) $k=0$ in the whole range $0 \leq w \leq w_{\mathrm{h}}$. At $c<c^{*}$ lacunar pores exist and according to Eqs. (5) and (6) $0<k \leq 1$. We assume that at $c<c^{*}$ as in the case $c>c^{*}$ when $k=0=$ constant as a function of $w, k$ does not also depend on water content, but can vary with clay content in the above range $0<k \leq 1$. We will see that experimental observations justify this assumption. Then, integrating Eq. (5) at any clay content over water content from the initial $w_{\mathrm{h}}$ value to a current $w$ value, and taking into account the initial conditions, $U_{\mathrm{lp}}\left(w_{\mathrm{h}}\right) \equiv U_{\mathrm{lph}}$ and $U_{\text {cp }}\left(w_{\mathrm{h}}\right)=w_{\mathrm{h}} / \rho_{\mathrm{w}}$ as well as the fact that $k$ does not depend on water content, we find for any given clay content a linear relation between the lacunar pore volume $\left(U_{\mathrm{lp}}(w)\right)$ and the clay pore volume $\left(U_{\mathrm{cp}}(w)\right)$ at shrinkage to be

$U_{\mathrm{lp}}(w)=U_{\mathrm{lph}}+k\left(w_{\mathrm{h}} / \rho_{\mathrm{w}}-U_{\mathrm{cp}}(w)\right), 0 \leq w \leq w_{\mathrm{h}}$.

\subsection{The Shrinkage Curve of an Intra-Aggregate Matrix $(\boldsymbol{U}(w))$ vs. the Shrinkage Curve of a Clay $(V(\bar{w}))($ Fig. 3)}

Although lacunar pores change in volume (Eq. (7)) during shrinkage they are emptied (if water filled) before the shrinkage starts (because of their size and capillarity). That is, at any water content $0 \leq w \leq w_{\mathrm{h}}$ of the intra-aggregate matrix, water is only contained in clay pores (Fig. 2). It follows a simple relation between the gravimetric water content $(\bar{w})$ of a pure clay (per unit mass of oven-dried clay) and that ( $w$ ) of the intra-aggregate matrix (Fig. 2) (per unit mass of ovendried matrix) containing the clay as

$w=\bar{w} c, 0 \leq \bar{w} \leq \bar{w}_{\mathrm{h}}, 0 \leq w \leq w_{\mathrm{h}}$

(where $c$ is the clay content of the matrix and soil) and a similar relation

$U_{\mathrm{cp}}(w)=V_{\mathrm{cp}}(\bar{w}) c, 0 \leq \bar{w} \leq \bar{w}_{\mathrm{h}}, 0 \leq w \leq w_{\mathrm{h}}$

between the specific volume $V_{\mathrm{cp}}$ of clay pores (per unit mass of oven-dried clay) and specific volume $U_{\text {cp }}$ of clay pores of the intra-aggregate matrix (Fig. 2) (per unit mass of ovendried intra-aggregate matrix) containing the clay. In addition, from Eq. (1)

$V_{\mathrm{cp}}(\bar{w})=V(\bar{w})-1 / \rho_{\mathrm{s}}$.

Thus, Eqs. (9), (10), and (8) determine $U_{\mathrm{cp}}(w)$ through $V(w / c)$. Similarly, Eqs. (7), (9), (10), and (8) determine $U_{\mathrm{lp}}(w)$ through $V(w / c)$. Finally, Eqs. (3), (7), (9), (10), and (8) determine the specific volume of the intra-aggregate matrix, $U(w)$ through the specific volume $V(w / c)$ of the clay contributing to the matrix (Fig. 2) as

$$
\begin{aligned}
& U(w)=1 / \rho_{\mathrm{s}}+U_{\mathrm{lph}}+k w_{\mathrm{h}} / \rho_{\mathrm{w}} \\
& +(1-k) c\left(V(w / c)-1 / \rho_{\mathrm{s}}\right), 0 \leq w \leq w_{\mathrm{h}} .
\end{aligned}
$$

Eq. (11) relates to any clay content. At $c<c^{*}$ in Eq. (11) $U_{\text {lph }}>0$ and $0<k=$ const $\leq 1$. At $c>c^{*}$ in Eq. (11) $U_{\mathrm{lph}}=0$ and $k=0$. Thus, there is the linear relation between $U(w)$ and $V(w / c)$.
Replacing $V(w / c)$ in Eq. (11) from Eq. (2) [23] one can obtain the following presentation of $U(w)$

$$
U(w)= \begin{cases}U_{\mathrm{z}}, & 0 \leq w \leq w_{\mathrm{z}} \\ U_{\mathrm{z}}+b\left(w-w_{\mathrm{z}}\right)^{2}, & w_{\mathrm{z}} \leq w \leq w_{\mathrm{n}} \\ 1 / \rho_{\mathrm{S}}+U_{1 \mathrm{ph}} & \\ +k w_{\mathrm{h}} / \rho_{\mathrm{w}} & w_{\mathrm{n}} \leq w \leq w_{\mathrm{h}} \\ +(1-k) w / \rho_{\mathrm{w}}, & \end{cases}
$$

$U_{\mathrm{z}}$ and $b$ are expressed through clay parameters (Eq. (2)) and the intra-aggregate matrix parameters (Eq. (11)). Here we are only interested in the qualitative view of $U(w)$ in comparison with the $V(\bar{w})$ dependence in Fig. (1a). Fig. (3) shows such a view of $U(w)$ at $0<k<1$ (i.e., for $c<c^{*}$ and $U_{\mathrm{lph}}>0$ ). The $w$ value along the water content axis in Fig. (3) is connected with $\bar{w}$ in Fig. (1a) by Eq. (8). In particular, $w_{\mathrm{z}}=\bar{w}_{\mathrm{z}} c, w_{\mathrm{n}}=\bar{w}_{\mathrm{n}} c$, and $w_{\mathrm{h}}=\bar{w}_{\mathrm{h}} c$.

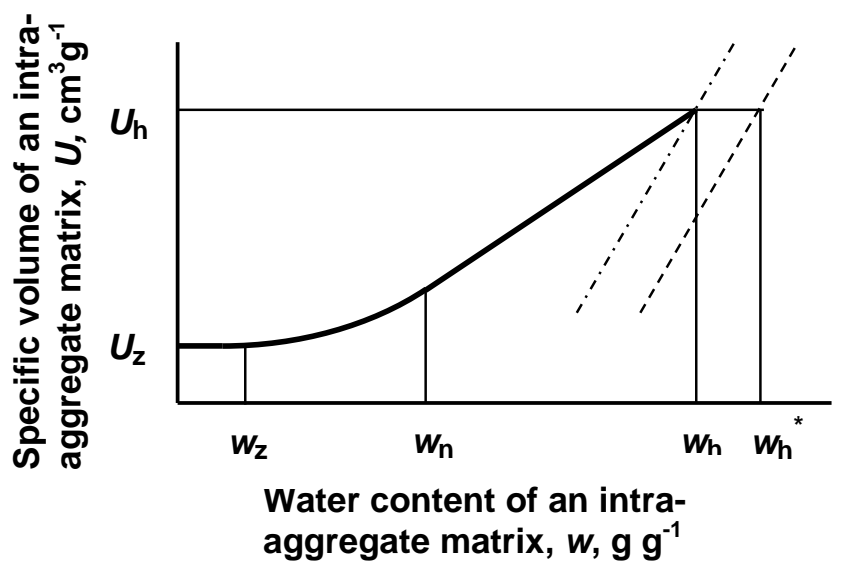

Fig. (3). Qualitative view of the shrinkage curve $U(w)$ of the intraaggregate matrix (corresponding to the shrinkage curve $V(\bar{w})$ of clay contributing to the matrix in Fig. (1a); with $w=\bar{w} c$ ). Lacunar factor $k$ is in the range $0 \leq k \leq 1$. The $k$ value depends on $c>c^{*}$ (Fig. 2a) or $c<c^{*}$ (Fig. 2b and 2c) and the lacunar pore volume in the last case. In the basic shrinkage area, $w_{\mathrm{n}}<w<w_{\mathrm{h}}$ the slope $\mathrm{d} U / \mathrm{d} w=(1-$ $k) / \rho_{\mathrm{w}} \leq 1 / \rho_{\mathrm{w}}$. At $k>0$ the shrinkage curve, $U(w)$ starts at the pseudo saturation (dash-dot) line; the $\left(w_{\mathrm{h}}{ }^{*}-w_{\mathrm{h}}\right)$ shear relative to the true saturation (dashed) line is connected with non-filled lacunar pores.

At first glance the presentations of Eqs. (2) and (12) as well as dependences $V(\bar{w})$ in Fig. (1a) and $U(w)$ in Fig. (3) are similar. Indeed, in both cases Fig. (1a) and Fig. (3) there are two linear sections and a "squared" section. However, one can also see two very essential qualitative differences between $U(w)$ (Eq. (12)) and $V(\bar{w})$ (Eq. (2)). The former difference relates to the slope of the $U(w)$ curve in the basic 
shrinkage area $\left(w_{\mathrm{n}} \leq w \leq w_{\mathrm{h}}\right)$ (Fig. 3) compared with the slope of the $V(\bar{w})$ curve in its basic shrinkage area $\left(\bar{w}_{\mathrm{n}} \leq \bar{w} \leq \bar{w}_{\mathrm{h}}\right)$ (Fig. 1a). The slope $\mathrm{d} V / \mathrm{d} \bar{w}=1 / \rho_{\mathrm{w}}$ at $\bar{w}_{\mathrm{n}} \leq \bar{w} \leq \bar{w}_{\mathrm{h}}$ (Eq. (2)) for any clay (Fig. 1a). Unlike that, according to Eq. (12) the slope

$$
\mathrm{d} U / \mathrm{d} w=(1-k) / \rho_{\mathrm{w}}, w_{\mathrm{n}} \leq w \leq w_{\mathrm{h}}
$$

and depends on the $k$ value (see Fig. 3). In turn, the $k$ factor depends on the clay content and characteristics of clay and silt-sand grains contributing to the soil (see Section 3.1). Only at $c>c^{*} \mathrm{~d} U / \mathrm{d} w=1 / \rho_{\mathrm{w}}$ in Fig. (3) in the total range $w_{\mathrm{n}} \leq w \leq w_{\mathrm{h}}$ similar to clay (Fig. 1a) because $k=0$. At $c<c^{*}$ (Fig. 3) the slope is constant and less than unity $\left((1-k) / \rho_{\mathrm{w}}\right)$ in the total range $w_{\mathrm{n}} \leq w \leq w_{\mathrm{h}}$. Equation (13) can be directly obtained from Eq. (6) because at $w_{\mathrm{n}} \leq w \leq w_{\mathrm{h}} \mathrm{d} U_{\mathrm{cp}}=\mathrm{d} w / \rho_{\mathrm{w}}$. The above analysis is necessary to understand the relations between $V(\bar{w})$ and $U(w)$.

The second qualitative difference relates to the position of the saturation line of the $U(w)$ curve (Fig. 3) unlike the position of the saturation line of the $V(\bar{w})$ curve (Fig. 1a). In the range $\bar{w}_{\mathrm{n}} \leq \bar{w} \leq \bar{w}_{\mathrm{h}}$ the shrinkage curve $V(\bar{w})$ of a disaggregated clay always coincides with its saturation line (see Eq. (2) and Fig. 1a). Unlike that, the point $U_{\mathrm{h}}=U\left(w_{\mathrm{h}}\right)$ of the shrinkage curve $U(w)$ of the intra-aggregate matrix (Fig. 3 ) is only situated on the true saturation line, $1 / \rho_{\mathrm{s}}+w / \rho_{\mathrm{w}}$ if $k=0$ and $U_{\text {lph }}=0$ (see Eq. (12) at $w_{\mathrm{n}} \leq w \leq w_{\mathrm{h}}$ ). This is realized for clay contents $c>c^{*}$ and corresponds to the absence of lacunar pores. If $k=$ const $>0$ (Fig. 3) lacunar pores exist, their volume remains empty, and the true saturation line, $1 / \rho_{\mathrm{s}}+w / \rho_{\mathrm{w}}$ is not reached at swelling. In this case $\left(c<c^{*}\right)$ the point $U_{\mathrm{h}}=U\left(w_{\mathrm{h}}\right)$ of the shrinkage curve $U(w)$ (Fig. 3) is situated on a 1:1 line (with unit slope) that is a pseudo saturation line.

It is worth emphasizing that both the above qualitative differences between $U(w)$ and $V(\bar{w})$ are direct consequences of lacunar pores existing in the intra-aggregate matrix (Fig. 2b) and the increase in lacunar pore volume $\left(U_{\mathrm{lp}}(w)\right)$ (Eqs. (7)-(10)) during shrinkage. At high clay content, $c>c^{*}$ when there are no lacunar pores (Fig. 2a), these qualitative features of $U(w)$ compared with $V(\bar{w})$ are absent; that is, the dashed and dash-dot lines in Fig. (3) coincide with each other and with $U(w)$ at $w_{\mathrm{n}} \leq w \leq w_{\mathrm{h}}$.

Note that at high clay content $\left(c>c_{*}\right)$ the shrinkage curve of the intra-aggregate matrix, $U(w)$ (Fig. 3) can be directly observed as the shrinkage curve of a clay paste with silt-sand admixture (e.g., [25]). However, at sufficiently small clay content (at $c<c^{*}$ ) the shrinkage curve $U(w)$ (Fig. 3), it seems, cannot be directly observed because of the quick formation of a superficial aggregate layer that is present in any sample along with an intra-aggregate matrix (Fig. 2b).

Finally, note that in the following consideration the shrinkage curve of the intra-aggregate matrix, $U(w)$ plays the part of an important auxiliary curve.

\section{THE SHRINKAGE CURVE OF AN AGGREGATE $\operatorname{SYSTEM}\left(U_{\mathrm{a}}(W)\right)$}

The shrinkage curve of an aggregate system is a correspondence between the total gravimetric water content $(W)$ and specific volume $\left(U_{\mathrm{a}}\right)$ of the system. Both consist of two contributions [4-6]. The aim of this section is to show, step by step, the transition from the $U(w)$ auxiliary curve to the shrinkage curve $U_{\mathrm{a}}(W)$.

\subsection{Contributions to the Total Water Content $(W)$ and Volume $\left(U_{\mathrm{a}}\right)$ of an Aggregate System}

According to Fig. (2) and assumptions from Section 1 the total water content of an aggregate system (and soil) $(W)$ includes contributions of the intra-aggregate matrix $\left(w^{\prime}\right)$ and interface layer $(\omega)$ as

$W=w^{\prime}+\omega$.

Structural and lacunar pores are empty at shrinkage because of their size and capillarity. Thus, the $w^{\prime}$ and $\omega$ contributions are interconnected because the interface clay pores giving the $\omega$ contribution and pores of intra-aggregate clay giving the $w^{\prime}$ contribution (Fig. 2) are at the same varying suction. We will consider $w^{\prime}$ to be an independent variable that varies in the range $0 \leq w^{\prime} \leq w_{\mathrm{h}}{ }^{\prime}$ where $w_{\mathrm{h}}{ }^{\prime}$ corresponds to the state of the maximum aggregate and soil swelling.

According to Fig. (2) and assumptions from Section 1 the specific volume of aggregates $\left(U_{\mathrm{a}}\right)$ also includes contributions of the intra-aggregate matrix $\left(U^{\prime}\right)$ and non-shrinking interface layer $\left(U_{\mathrm{i}}\right) . U^{\prime}$ and $U_{\mathrm{a}}$ can also be considered as functions of the independent parameter $w^{\prime}$. Thus,

$U_{\mathrm{a}}\left(w^{\prime}\right)=U^{\prime}\left(w^{\prime}\right)+U_{\mathrm{i}}, 0 \leq w^{\prime} \leq w_{\mathrm{h}}{ }^{\prime}$.

\subsection{Contribution of the Intra-Aggregate Matrix $\left(U^{\prime}\left(w^{\prime}\right)\right)$ to the Aggregate Volume $\left(U_{\mathrm{a}}\right)$ vs. the Shrinkage Curve of the Intra-Aggregate Matrix $(U(w))$ (Fig. 4)}

The $U^{\prime}\left(w^{\prime}\right)$ dependence in itself (Fig. 4) is not a real shrinkage curve because it only gives one contribution (of the intra-aggregate matrix; Fig. (2) to the specific volume, $U_{\mathrm{a}}$ (another one is $U_{\mathrm{i}}$, Eq. (15)). This is why the $U^{\prime}\left(w^{\prime}\right)$ curve is situated below the saturation line in Fig. (4). However, $U^{\prime}\left(w^{\prime}\right)$ is directly and simply connected with the auxiliary shrinkage curve of the intra-aggregate matrix, $U(w)$ (Fig. (3); Section 3). $U^{\prime}\left(w^{\prime}\right)$ and $U(w)$ only differ by normalization. $U^{\prime}$ and $w^{\prime}$ are the specific volume and water content contributions of the intra-aggregate matrix per unit mass of the ovendried soil as a whole, including the solid mass of the interface layer (see Fig. 2). $U$ and $w$, however, are the specific volume and water content of the same intra-aggregate matrix per unit mass of the oven-dried matrix itself, i.e., without the solid mass of the interface layer (see Fig. 2). It follows that the water content values along the $w$ and $w^{\prime}$ axes in Fig. (4) are connected as

$w^{\prime}=w / K$,

and corresponding $U$ and $U^{\prime}$ values as

$U^{\prime}=U / K$ 

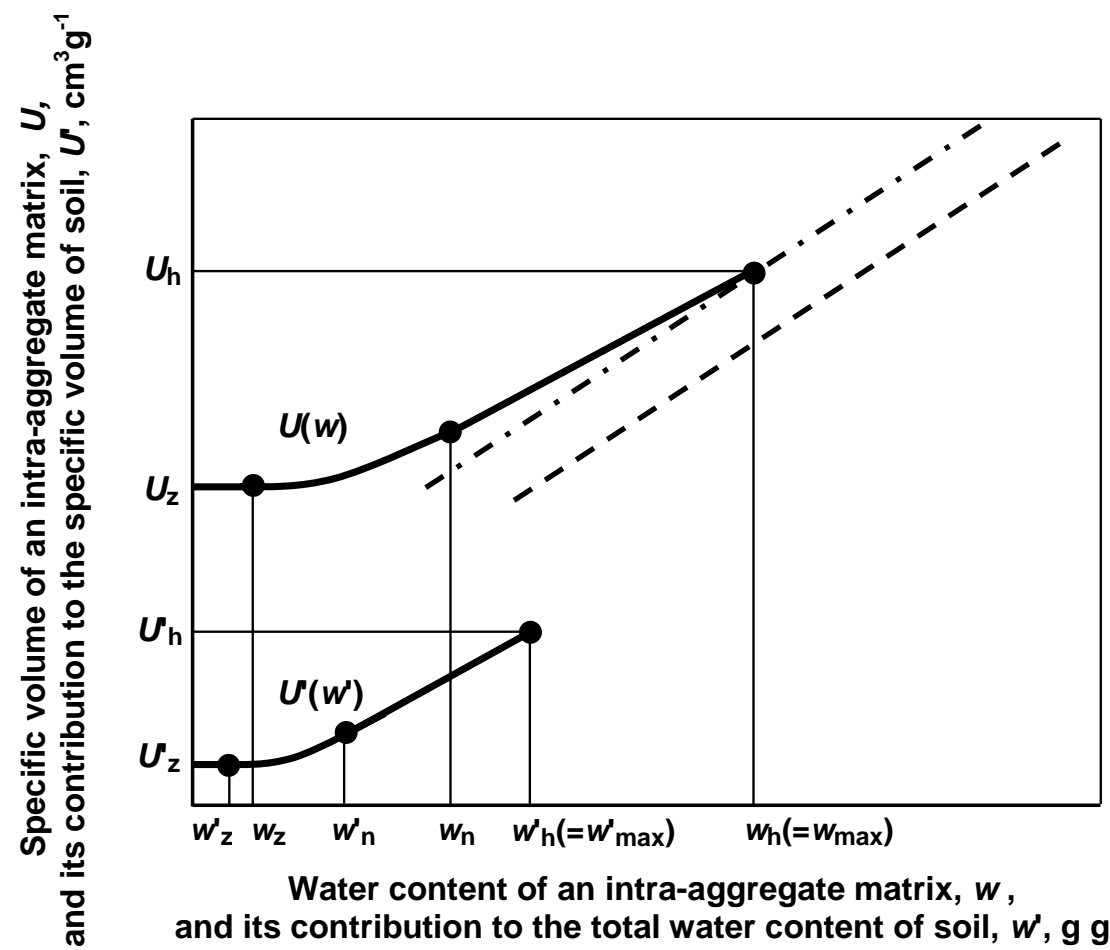

Water content of an intra-aggregate matrix, $w$, and its contribution to the total water content of soil, $w^{\prime}, \mathrm{g} \mathrm{g}^{-1}$

Fig. (4). Transition from the shrinkage curve, $U(w)$ of the intra-aggregate matrix to the contribution, $U^{\prime}\left(w^{\prime}\right)$ of the intra-aggregate matrix to the specific volume of an aggregate system $\left(U_{\mathrm{a}}\right)$ and soil $(Y)$, for clay contents $c<c^{*}$, based on Eqs. (16)-(18). In particular, $w_{\mathrm{z}}^{\prime}=w_{\mathrm{z}} / K$, $w_{\mathrm{n}}^{\prime}=w_{\mathrm{n}} / K, w_{\mathrm{h}}^{\prime}=w_{\mathrm{h}} / K$. Dashed and dash-dot lines are as in Fig. (1).

where $K>1$ is the ratio of the aggregate solid mass to the solid mass of the intra-aggregate matrix (i.e., the solid mass of aggregates without the interface layer, see Fig. (2). Hence, the relation between $U^{\prime}\left(w^{\prime}\right)$ and $U(w)$ is
$U^{\prime}\left(w^{\prime}\right)=U\left(w^{\prime} K\right) / K, 0 \leq w^{\prime} \leq w_{\mathrm{h}}{ }^{\prime}$.

Thus, the $U^{\prime}\left(w^{\prime}\right)$ curve (Fig. 4) is expressed through the auxiliary shrinkage curve $U(w)$ (Section 3 ) and $K$ ratio. The latter is connected with the $U_{\mathrm{i}}$ contribution (see Section 4.3).
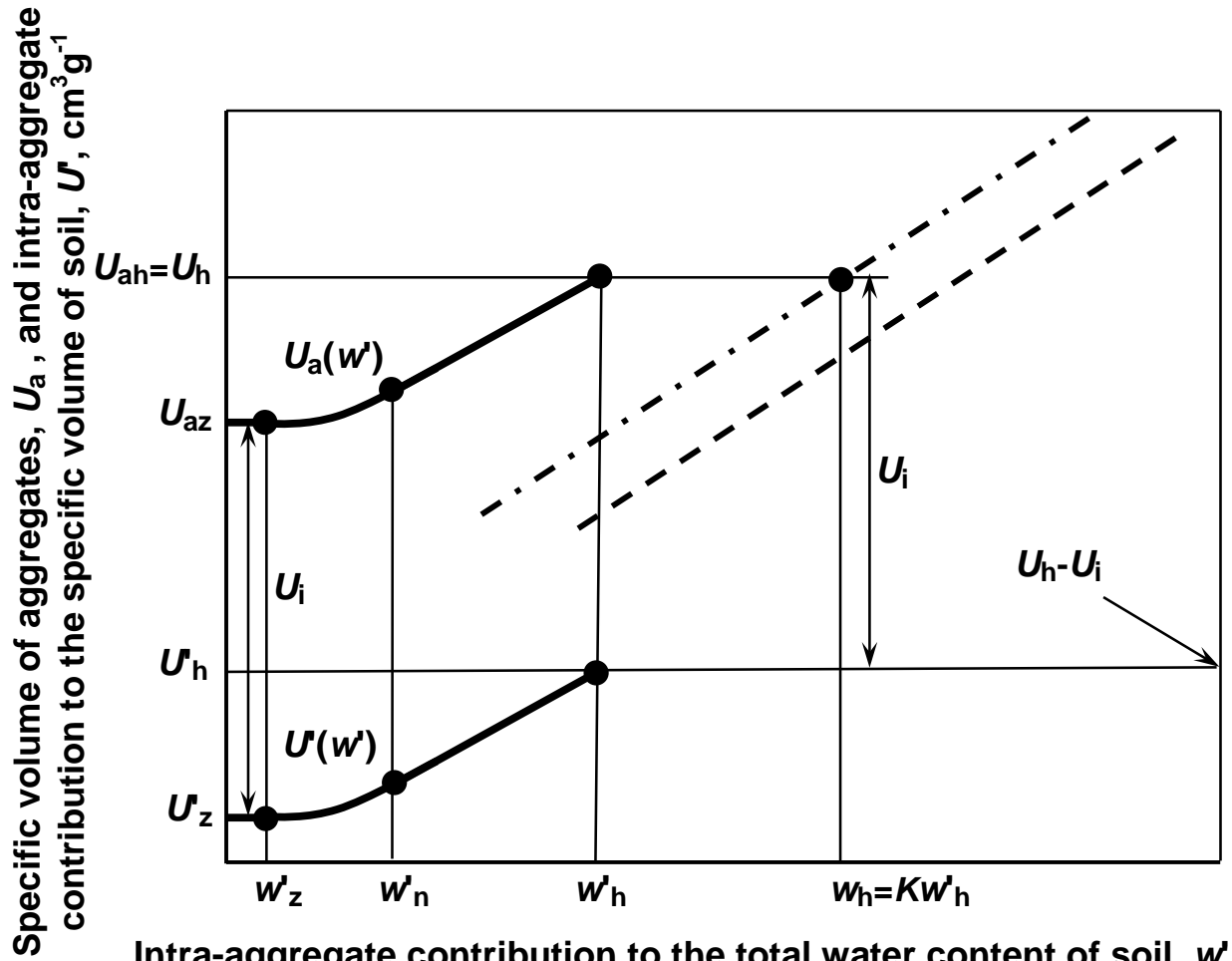

Intra-aggregate contribution to the total water content of soil, $\mathbf{w}^{\prime}, \mathbf{g ~ g}^{-1}$

Fig. (5). Transition from the contribution, $U^{\prime}\left(w^{\prime}\right)$ of the intra-aggregate matrix to the aggregate shrinkage curve in coordinates $U_{\mathrm{a}}$ and $w^{\prime}$ at $c<c^{*}$, based on Eq. (15) and accounting for the condition of Eq. (19). Dashed and dash-dot lines are as in Fig. (1). 
According to Eqs. (16) and (18) $\mathrm{d} U^{\prime} / \mathrm{d} w^{\prime}=\mathrm{d} U / \mathrm{d} w$ (Fig. 4; $\left.0 \leq w^{\prime} \leq w_{\mathrm{h}}{ }^{\prime} ; 0 \leq w \leq w_{\mathrm{h}}=K w_{\mathrm{h}}{ }^{\prime}\right)$. In particular, the basic shrinkage area, $w_{\mathrm{n}} \leq w \leq w_{\mathrm{h}}$ of $U(w)$ (Fig. 4) where $\mathrm{d} U / \mathrm{d} w=(1-k) / \rho_{\mathrm{w}}$ (Eq. (13)) corresponds to the basic shrinkage area, $w_{\mathrm{n}}{ }^{\prime}=w_{\mathrm{n}} / K \leq w^{\prime} \leq w_{\mathrm{h}}{ }^{\prime}$ of $U^{\prime}\left(w^{\prime}\right)$ (Fig. 4) where $U^{\prime}\left(w^{\prime}\right)$ has the similar slope, $(1-k) / \rho_{\mathrm{w}}$. For the sake of simplicity Fig. (4) only shows the $U(w) \rightarrow U^{\prime}\left(w^{\prime}\right)$ transition for the case $c<c^{*}$ when $0<k \leq 1$ (Fig. 3). At $k=0\left(c>c^{*}\right)$ the slope of $U(w)$ and $U^{\prime}\left(w^{\prime}\right)$ in corresponding basic shrinkage areas coincide with the slope of the saturation line (the dashed line in Fig. (4) that at $k=0$ coincides with dash-dot line).

4.3. The Shrinkage Curve of Aggregate System in Coordinates $U_{\mathrm{a}}$ and $\boldsymbol{w}^{\prime}$ vs. the Contribution of Intra-Aggregate Matrix $\left(U^{\prime}\left(w^{\prime}\right)\right)$ (Fig. 5)

According to Eq. (15) the shrinkage curve $U_{\mathrm{a}}\left(w^{\prime}\right)$ only differs from the $U^{\prime}\left(w^{\prime}\right)$ curve (Section 4.2, Fig. 4) by the constant shear $U_{\mathrm{i}}$ along the axis of the specific volume (Fig. 5). This means that all that was said in Section 4.2 with respect to the $\mathrm{d} U^{\prime} / \mathrm{d} w^{\prime}$ slope in the basic shrinkage area $w_{\mathrm{n}}{ }^{\prime} \leq w^{\prime} \leq w_{\mathrm{h}}{ }^{\prime}$ (Fig. 4) and the slope value connection with clay content, also relates to the $\mathrm{d} U_{\mathrm{a}} / \mathrm{d} w^{\prime}$ slope in the same area (Fig. 5).

The $U_{\mathrm{a}}\left(w^{\prime}\right)$ curve (Fig. 5) has an uncustomary view because (unlike $U^{\prime}\left(w^{\prime}\right)$ ) it was presented using an unusual (for $U_{\text {a }}$ volume) $w^{\prime}$ coordinate. The presentation in usual coordinates, $U_{\mathrm{a}}(W)$ is determined by a $W\left(w^{\prime}\right)$ dependence that changes the scale along the water content axis compared to $w^{\prime}$ (see Section 4.4).

In connection with the mutual situation of the $U(w)$ curve (Fig. 3 and Fig. 4) and $U_{\mathrm{a}}\left(w^{\prime}\right)$ curve (Fig. 5), it is important to emphasize that the $U_{\mathrm{h}}=U\left(w_{\mathrm{h}}\right)\left(\right.$ Figs. 3-5) and $U_{\mathrm{ah}}=U_{\mathrm{a}}\left(w_{\mathrm{h}}{ }^{\prime}\right)$ (Fig. 5) values coincide as

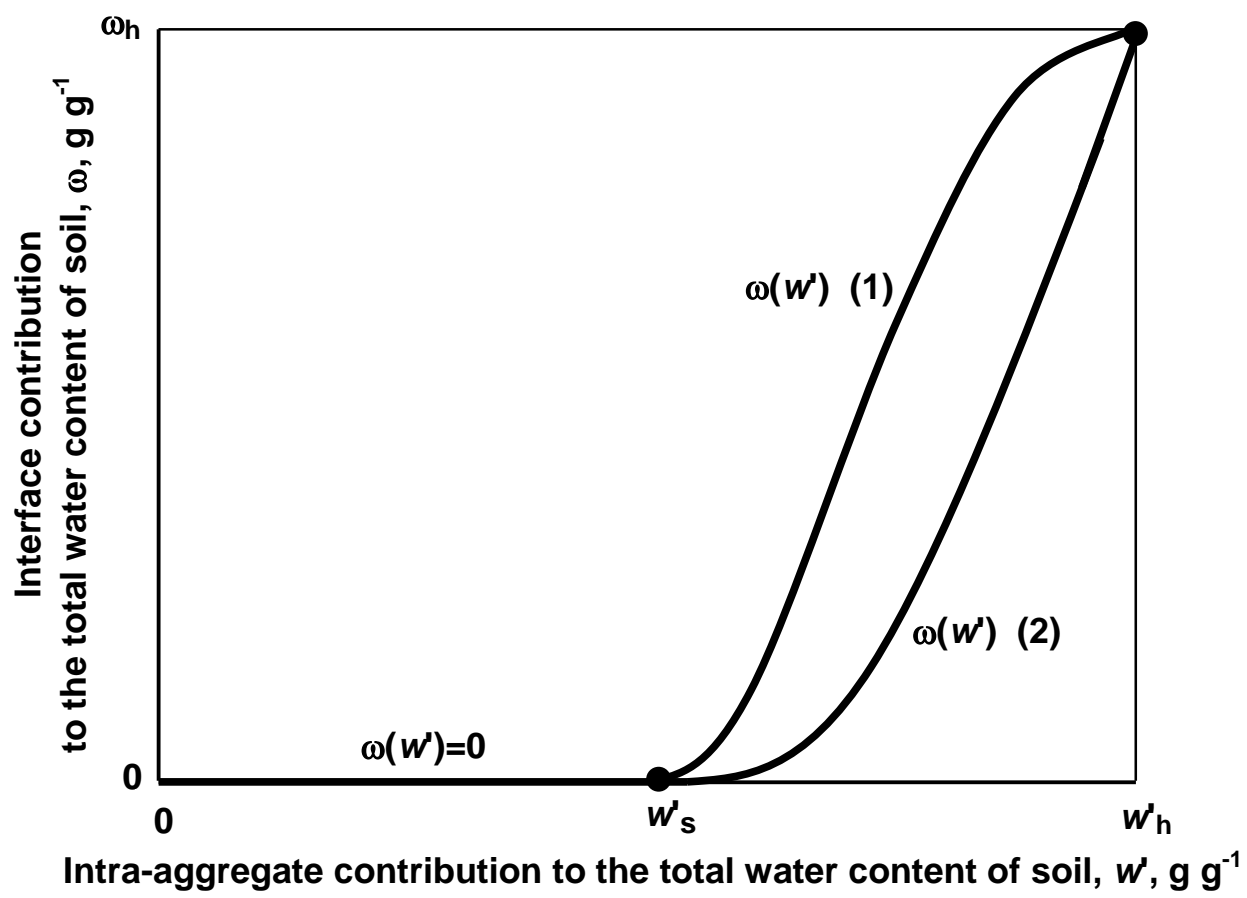

Fig. (6). The qualitative view of two simplest possible variants of the $\omega\left(w^{\prime}\right)$ dependence (entering Eq. (14)). $\omega_{\mathrm{h}}$ is the maximum water content of interface layer of aggregates. $w_{\mathrm{s}}{ }^{\prime}$ corresponds to the completion of the structural shrinkage.
$U_{\mathrm{ah}}=U_{\mathrm{h}}$

because the water contents and specific volumes of the two aggregate parts - the non-shrinking interface layer and intraaggregate matrix (Fig. 2) - coincide at maximum soil swelling (the shrinkage start point). Replacing in relation, $U_{\mathrm{i}}=U_{\mathrm{ah}}-U_{\mathrm{h}}{ }^{\prime}$ (see Eq. (15) at $w^{\prime}=w_{\mathrm{h}}{ }^{\prime}$ ) $U_{\text {ah }}$ from Eq. (19) and $U_{\mathrm{h}}{ }^{\prime}=U_{\mathrm{h}} / K$ (from Eq. (17) at $w^{\prime}=w_{\mathrm{h}}{ }^{\prime}$ ) we obtain the important relation between the specific volume of the interface layer, $U_{\mathrm{i}}$ (Fig. 2 and Fig. 5), the specific volume of the intraaggregate matrix $\left(U_{\mathrm{h}}\right)$ (or specific volume of aggregates ( $\left.U_{\text {ah }}\right)$ as a whole) at maximum swelling, and the $K$ ratio as

$U_{\mathrm{i}}=U_{\mathrm{h}}(1-1 / K)$.

This relation reflects the mutual arrangement of curves $U(w), U^{\prime}\left(w^{\prime}\right)$, and $U_{\mathrm{a}}\left(w^{\prime}\right)$ in Figs. (3-5).

For the sake of simplicity Fig. (5) only shows the $U^{\prime}\left(w^{\prime}\right) \rightarrow U_{\mathrm{a}}\left(w^{\prime}\right)$ transition for the case $c<c^{*}$ when $0<k \leq 1$ and $U(w)$ corresponds to Fig. (3). At $k=0\left(c>c^{*}\right)$ the slope of $U^{\prime}\left(w^{\prime}\right)$ and $U_{\mathrm{a}}\left(w^{\prime}\right)$ in Fig. (5) in the $w_{\mathrm{n}}{ }^{\prime} \leq w^{\prime} \leq w_{\mathrm{h}}{ }^{\prime}$ area coincide with the slope of the dashed and dash-dot lines that also coincide with each other.

\subsection{The Shrinkage Curve of an Aggregate System in Co- ordinates $U_{\mathrm{a}}$ and $\boldsymbol{W}$ vs. the Same Shrinkage Curve in Co- ordinates $U_{\mathrm{a}}$ and $w^{\prime}$ (Fig. 7)}

We consider $w^{\prime}$ to be an independent variable (Section $4.1)$. Then the contribution of the interface layer to the total water content $W$ is $\omega=\omega\left(w^{\prime}\right)$ (see Eq. (14)). This dependence can be found quantitatively for the two possible types of modified pore-size distribution in the interface clay [4-6] from the pore-size distribution of the clay $[23,26]$ and from the dependence of the maximum size of water-filled clay pores on water content $w^{\prime}$ [27]. However, the qualitative 
view of the $\omega\left(w^{\prime}\right)$ dependence (Fig. 6) is sufficient for the aims of this work. This qualitative view flows out of simple considerations. $\omega\left(w_{\mathrm{h}}{ }^{\prime}\right)=\omega_{\mathrm{h}}$ (Fig. 6) gives the maximum water content of the non-shrinking interface layer when shrinkage starts. The interface clay pores are totally emptied during shrinkage at some $w_{\mathrm{s}}{ }^{\prime}$ (Fig. 6) where $w_{\mathrm{n}}{ }^{\prime}<w_{\mathrm{s}}{ }^{\prime}<w_{\mathrm{h}}{ }^{\prime}\left(w_{\mathrm{n}}{ }^{\prime}\right.$ is the air-entry point of the intra-aggregate matrix; see Fig. (5)), i.e., $\omega\left(w^{\prime}\right)=0$ at $w^{\prime} \leq w_{\mathrm{s}}{ }^{\prime}$ (Fig. 6). The $w_{\mathrm{s}}{ }^{\prime}$ point is the final one of structural shrinkage and the initial one of basic shrinkage (Fig. 7). It is obvious that the $\omega\left(w^{\prime}\right)$ dependence should be smooth at $w^{\prime}=w_{\mathrm{s}}{ }^{\prime}$ ( $\mathrm{dù} / \mathrm{d} w_{w^{\prime}=w_{\mathrm{s}}^{\prime}}=0$; Fig. (6). Then, the two curves in Fig. (6) show two of the simplest, geometrically possible variants of such $\omega\left(w^{\prime}\right)$ dependence with (curve 1) and without (curve 2) inflection point.

The total water content $W$ as a function of $w^{\prime}$ is $W\left(w^{\prime}\right)=w^{\prime}+\omega\left(w^{\prime}\right)$ (Eq. (14)) where $\omega\left(w^{\prime}\right)$ is from Fig. (6). The $W\left(w^{\prime}\right)$ dependence changes the scale along the water content axis compared to $w^{\prime}$ (Fig. 7). At $0 \leq w^{\prime} \leq w_{\mathrm{s}}{ }^{\prime} W=w^{\prime}$ (Fig. 7). This means that $U_{\mathrm{a}}\left(w^{\prime}\right)$ at $0 \leq w^{\prime} \leq w_{\mathrm{s}}{ }^{\prime}$ in Fig. (5) and Fig. (7) quantitatively coincides with $U_{\mathrm{a}}(W)$ at $0 \leq W \leq W_{\mathrm{s}}$ (i.e., in particular, in the basic shrinkage area, $\left.w_{\mathrm{n}}{ }^{\prime} \leq w{ }^{\prime} \leq w_{\mathrm{s}}{ }^{\prime}\right)$ in Fig. (7). Only in the $w_{\mathrm{s}}{ }^{\prime} \leq w^{\prime} \leq w_{\mathrm{h}}{ }^{\prime}$ and $W_{\mathrm{s}} \leq W \leq W_{\mathrm{h}}$ ranges of the structural shrinkage do the presentations $U_{\mathrm{a}}\left(w^{\prime}\right)$ and $U_{\mathrm{a}}(W)$ (Fig. 7) differ. The two variants of $U_{\mathrm{a}}(W)$ in Fig. (7) correspond to the two variants of $\omega\left(w^{\prime}\right)$ in Fig. (6). Thus, the model predicts two possible qualitatively different types of reference shrinkage curve in the structural shrinkage area. Note that both the convex upward shape of $U_{\mathrm{a}}(W)$ in the structural shrinkage area $\left(W>W_{\mathrm{s}}\right)$ and two types of $U_{\mathrm{a}}(W)$ in the struc- tural shrinkage area (Fig. 7) originate from the existence of the non-shrinking interface layer $\left(U_{\mathrm{i}}\right.$ addition to $U_{\mathrm{a}}$, Eq. (15)) and its dewatering (Fig. 6) depending on its pore-size distribution.

As noted above, at $W \leq W_{\mathrm{s}}$ and $w^{\prime} \leq w_{\mathrm{s}}{ }^{\prime}, W=w^{\prime}$ (Fig. 7) and $U_{\mathrm{a}}(W)=U_{\mathrm{a}}\left(w^{\prime}\right)$. Hence, the slope of the observed reference shrinkage curve, $\mathrm{d} U_{\mathrm{a}} / \mathrm{d} W$ in the observed basic shrinkage area, $W_{\mathrm{n}} \leq W \leq W_{\mathrm{s}}\left(w_{\mathrm{n}}{ }^{\prime} \leq w^{\prime} \leq w_{\mathrm{s}}{ }^{\prime}\right.$, see Fig. (7)) is also given by $(1-k) / \rho_{\mathrm{w}}$ as $\mathrm{d} U^{\prime} / \mathrm{d} w^{\prime}$ and $\mathrm{d} U_{\mathrm{a}} / \mathrm{d} w^{\prime}$ (see the end of Section 4.2 and beginning of Section 4.3). This means that all that was said in Section 4.2 with respect to the $\mathrm{d} U^{\prime} / \mathrm{d} w^{\prime}$ slope in the basic shrinkage area $w_{\mathrm{n}}{ }^{\prime} \leq w^{\prime} \leq w_{\mathrm{h}}{ }^{\prime}$ (Fig. 4) and the slope value connection with clay content, also relate to the $\mathrm{d} U_{\mathrm{a}} / \mathrm{d} W$ slope in the same area, $W_{\mathrm{n}} \leq W \leq W_{\mathrm{s}}$ (Fig. 7).

In connection with the mutual situation of the $U(w)$ curve (Fig. 3 and Fig. 4), the $U_{\mathrm{a}}\left(w^{\prime}\right)$ curve (Fig. 5), and the $U_{\mathrm{a}}(W)$ curve (Fig. 7), it is important to emphasize that $w_{\mathrm{h}}$ (Figs. 3-5) and $W_{\mathrm{h}}$ (Fig. 7) coincide as

$W_{\mathrm{h}}=w_{\mathrm{h}}$

because the water contents and specific volumes of the two aggregate parts - the non-shrinking interface layer and intra-aggregate matrix (Fig. 2) - coincide at maximum soil swelling (the shrinkage start point). Accounting for $w_{\mathrm{h}}=K w_{\mathrm{h}}{ }^{\prime}$ (Eq. (16)) and $W_{\mathrm{h}}-w_{\mathrm{h}}{ }^{\prime}=\omega_{\mathrm{h}}$ (Eq. (14)) Eq. (21) leads to a relation that is equivalent to Eq. (20).

Finally, in the case of the sufficient connectivity of lacunar pores the $U_{\mathrm{a}}(W)$ shrinkage curve can reach the true saturation line and have a horizontal section as a result of their filling at water contents $W_{\mathrm{h}} \leq W \leq W_{\mathrm{h}}{ }^{*}$ (Fig. 7).

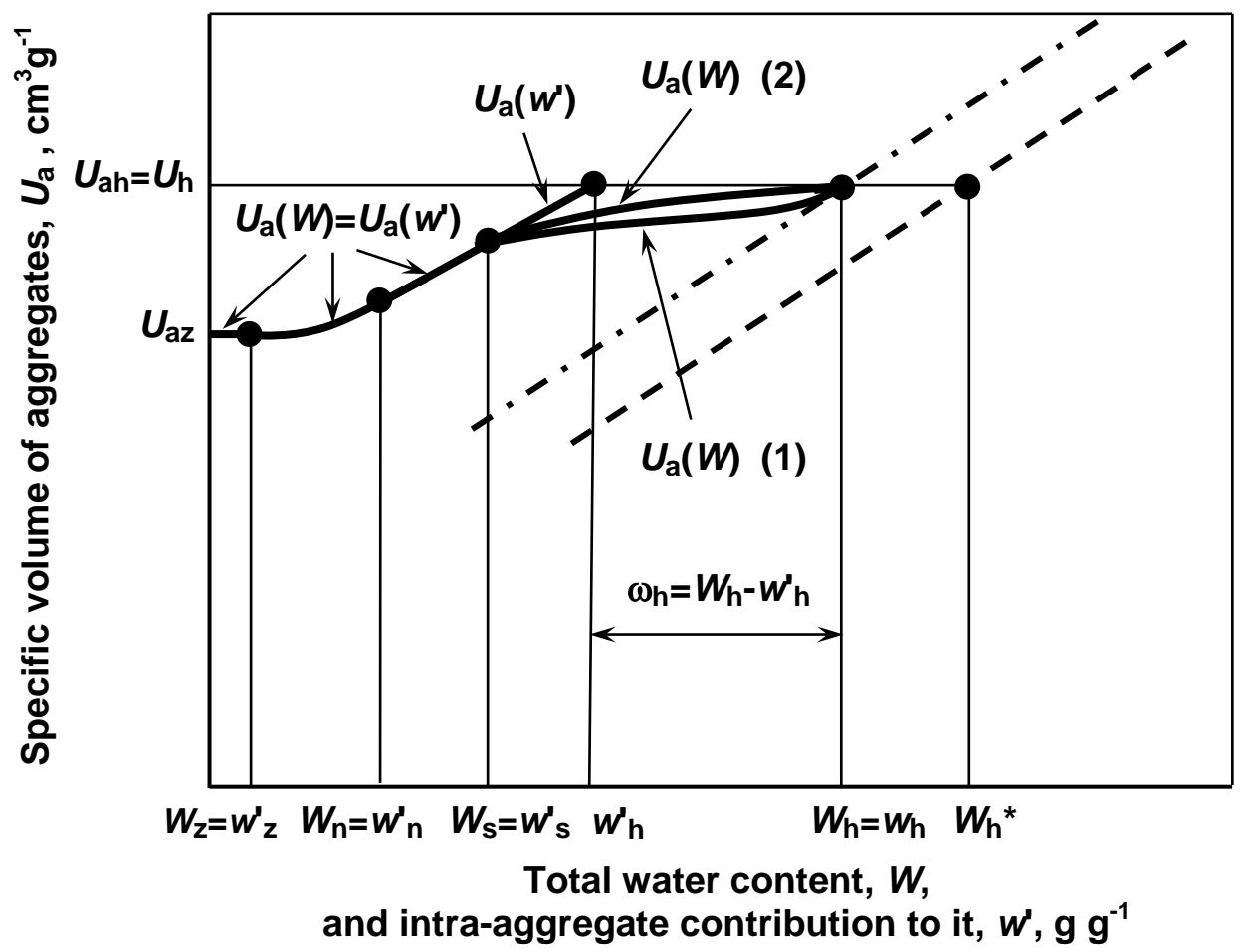

Fig. (7). Transition from the aggregate shrinkage curve in coordinates $U_{\mathrm{a}}$ and $w^{\prime}$ to that in coordinates $U_{\mathrm{a}}$ and $W$, at $c<c^{*}$. Dashed and dashdot lines are as in Fig. (1). 
For the sake of simplicity Fig. (7) only shows the $U_{\mathrm{a}}\left(w^{\prime}\right) \rightarrow U_{\mathrm{a}}(W)$ transition for the case $c<c^{*}$ when $0<k \leq 1$, and the $U_{\mathrm{a}}(W)$ curve starts at a pseudo saturation line (at $W=W_{\mathrm{h}}$ ).

5. THE SHRINKAGE CURVE OF A SOIL (Y(W)) VS. THE AGGREGATE SYSTEM SHRINKAGE CURVE $\left(U_{\mathrm{a}}(W)\right)$ (Fig. 8)

The specific volume of soil, $Y(W)$ only differs from the specific volume of an aggregate system, $U_{\mathrm{a}}(W)$ by the specific volume $U_{\mathrm{s}}$ of the inter-aggregate (structural) pores as

$Y(W)=U_{\mathrm{a}}(W)+U_{\mathrm{s}}$.

In the case of the reference shrinkage curve (by its definition) $U_{\mathrm{s}}$ does not depend on water content $W$ (see Section 1). Thus, the soil reference shrinkage curve, $Y(W)$ is totally similar in shape to the aggregate shrinkage curve, $U_{\mathrm{a}}(W)$ (Fig. 8) with the addition of a horizontal section in the range $W_{\mathrm{h}} \leq W \leq W_{\mathrm{m}}$. This section corresponds to the emptying of the structural pores (if water filled), and relations $U_{\mathrm{s}}=Y_{\mathrm{z}^{-}}$ $U_{\mathrm{az}}=\left(W_{\mathrm{m}}-W_{\mathrm{h}}\right) / \rho_{\mathrm{w}}($ see Fig. 8) take place.

Depending on lacunar pore connectivity the $Y(W)$ curve can start on a pseudo saturation line (at $W=W_{\mathrm{m}}$ in Fig. 8) or reach the true saturation line and have an additional horizontal section in the range $W_{\mathrm{m}} \leq W \leq W_{\mathrm{m}}{ }^{*}$ (Fig. 8) as a result of lacunar pore filling.

In the force of the similarity between $Y(W)$ and $U_{\mathrm{a}}(W)$ (Fig. (8); Eq. (22)) it is obvious that in the basic shrinkage area $\left(W_{\mathrm{n}} \leq W \leq W_{\mathrm{s}}\right)$ the slope $\mathrm{d} Y / \mathrm{d} W=\mathrm{d} U_{\mathrm{a}} / \mathrm{d} W=(1-k) / \rho_{\mathrm{w}}$ and also depends on the range of clay content: $c<c^{*},(0<k \leq 1$; the lacunar pore volume is increasing with drying) or $c>c^{*}(k=0$; lacking lacunar pores). It also follows from the same similarity that both the convex upward shape of $Y(W)$ in the struc- tural shrinkage area $\left(W>W_{\mathrm{s}}\right)$ and the two types of $Y(W)$ in the structural shrinkage area (Fig. (8) only shows type 2 of $Y(W)$ ) originate from the existence of the non-shrinking interface layer of aggregates and its dewatering (Fig. 6) depending on its pore-size distribution.

Worthy of special note is that the experimentally observed constancy of the shrinkage curve slope of a soil in the basic shrinkage area (feature (c) in Section 1), in combination with the theoretically predicted expression for the slope $\left(\mathrm{d} Y / \mathrm{d} W=(1-k) / \rho_{\mathrm{w}}\right)$, do justify the above important assumption (Section 3.1) according to which the lacunar factor, $k$ does not depend on water content.

Finally, note that the $U_{\mathrm{s}} \cong 0$ value reflects a broad spectrum of practically important situations when the specific volume of structural pores, $U_{\mathrm{s}}$ is rather less than the specific volume of interface clay pores, $U_{\mathrm{i}} \Pi(\Pi$ is the non-shrinking porosity of the interface clay). In this case $Y(W) \cong U_{\mathrm{a}}(W)$ (Figs. 7 and 8). If $U_{\mathrm{s}}<<U_{\mathrm{i}} \Pi$ the structural water content (before shrinkage starts) is rather less than the interface water content.

For the sake of simplicity Fig. (8) only shows the transition from $U_{\mathrm{a}}(W)$ to $Y(W)$ in the case that was indicated in Fig. (1b) when $c<c^{*}, 0<k \leq 1$, and the $Y(W)$ curve starts at the pseudo saturation line.

\section{DATA TO BE USED}

It is worth reiterating that the data that we use for comparison with theoretical results, relate to the qualitative aspects of the shrinkage curve shape (characteristic features from (a) to (d) from Section 1). Corresponding data are available from numerous soil shrinkage publications, for

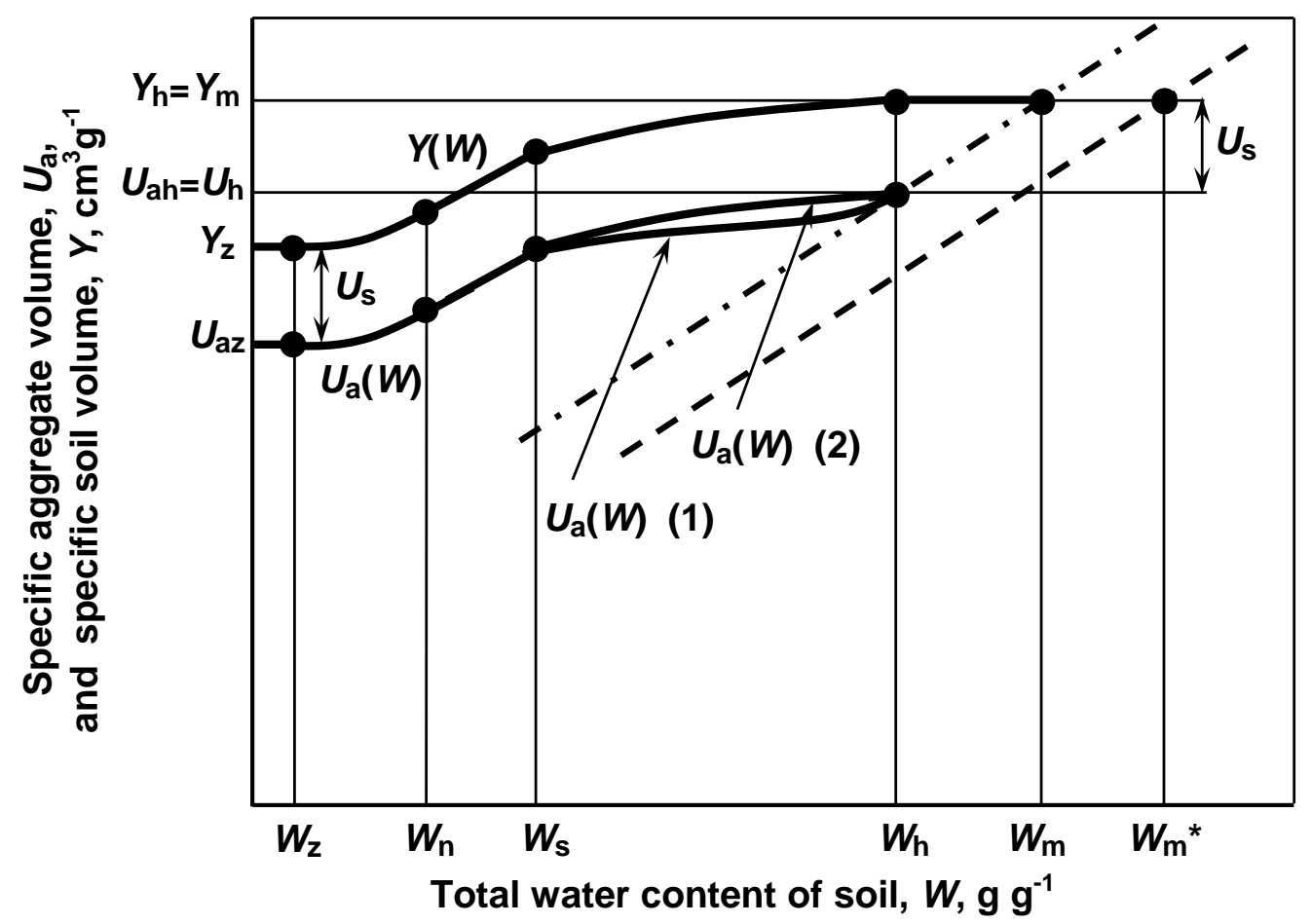

Fig. (8). Transition from the aggregate shrinkage curve, $U_{\mathrm{a}}(W)$ to the soil reference shrinkage curve, $Y(W)$, at $c<c^{*}$, based on Eq. (22). Dashed and dash-dot lines are as in Fig. (1). 
instance, from [1, 2, 28]. The qualitative aspects of the shrinkage curve shape from the available publications are presented in Fig. 1 in a generalized form.

\section{RESULTS AND DISCUSSION}

We assumed two new features of the intra-aggregate structure - the non-shrinking surface (interface) aggregate layer with varying water content and intra-aggregate lacunar pores with varying volume (Fig. 2). Then, we visually showed (Figs. 3-8) that the features lead to a number of qualitative peculiarities of the shape of the reference shrinkage curve of an aggregated soil. These qualitative physical effects of the new intra-aggregate structure concepts are as follows:

The existence of the non-shrinking superficial aggregate layer (Fig. (2); see [29]) (interface layer) leads to the convex upward shape of the reference shrinkage curve in the structural shrinkage area (see the sequence of Figs. (3-8)).

(ii) Dewatering of the non-shrinking interface layer of aggregates (Fig. 6) depending on its pore-size distribution leads to the specific course (with varying slope $<1)$ and two possible types of reference shrinkage curve in the structural shrinkage area (see curves 1 and 2 in Fig. (7)).

(iii) The existence and increase of the lacunar pore volume inside the intra-aggregate matrix (Fig. 2b) with a decrease in water content and depending on clay content, lead to the reference shrinkage curve slope being equal to or less than unity in the basic shrinkage area (see the sequence of Figs. (3-8)).

(iv) The existence and increase of the lacunar pore volume inside the intra-aggregate matrix (Fig. 2b) with a decrease in water content and depending on clay content, leads to a possible shear of the true saturation line relative to the pseudo saturation line (see the sequence of Figs. (3-8)).

One can now compare the results of predicting the qualitative peculiarities of the shrinkage curve shape (from (i) to (iv)) with results of numerous observations (see Section 6) that were formulated in Section 1 as points (a)-(d) [4-6] and as visually shown in Fig. (1). The comparison reveals the total coincidence between the predicted ((i)-(iv)) and observed $((\mathbf{a})-(\mathbf{d}))$ peculiarities of the shape of the shrinkage curve.

Thus, a major result of this work is the qualitative explanation of the origin of the observed qualitative differences between a clay shrinkage curve and the shrinkage curve of the soil containing it, based on the new assumed features of an intra-aggregate structure: the existence of lacunar pores and the increase in their volume during shrinkage as well as the existence of the deformable, but non-shrinking surface layer of aggregates and its dewatering during shrinkage.

The qualitative explanation of the $V(\bar{w})$ to $Y(W)$ transition is important for the physical understanding of the interconnections between an intra-aggregate structure and a soil shrinkage curve, even though one can quickly measure the shrinkage curve and even though there are good fitting approximations for the shrinkage curve. In general, observed shrinkage curves can quantitatively differ from the reference shrinkage curve due to crack existence (for sufficiently large samples), but qualitatively they have the same characteristic features that are explained above.

\section{CONCLUSION}

This work shows how a clay shrinkage curve turns into a soil shrinkage curve. Assumptions about an increase in lacunar pore volume and dewatering of a non-shrinking superficial aggregate layer at soil shrinkage enable one to qualitatively explain the origin of the observed peculiarities of the shrinkage curve shape of aggregated soils. Conversely, these observed peculiarities suggest the indicated new features of an intra-aggregate structure. The physical understanding of the transformation of the clay shrinkage curve to the soil shrinkage curve and of the new features of the intraaggregate structure underlying this transformation, are essential for numerous applications; first of all, for the physical modeling of soil shrinkage, water retention, hydraulic conductivity, water flow, and solute transport. In addition, the concepts and results of the model can also be useful for the physical explanation of crack contribution into a measured shrinkage curve $[30,31]$, the hysteretic shrinkage-swelling phenomenon, the effects of compaction and consolidation on soil shrinkage-swelling in the field, the effects of the nontotal closing shrinkage cracks at soil wetting in field conditions, and soil crusting.

\section{NOTATION}

$a \quad=$ coefficient in Eq. (2) $\left(\mathrm{cm}^{3} \mathrm{~g}^{-1}\right)$

$b \quad=$ coefficient in Eq. (12) $\left(\mathrm{cm}^{3} \mathrm{~g}^{-1}\right)$

$c \quad=$ weight fraction of clay solids of the total solids (clay-silt-sand) (dimensionless)

$c^{*} \quad=$ critical clay content; at $c>c^{*}$ lacunar pores are absent at any water content (dimensionless)

$K=$ ratio of aggregate solid mass to solid mass of intraaggregate matrix (dimensionless)

$k \quad=$ lacunar factor entering Eqs. (5) and (6) (dimensionless)

$p \quad=$ porosity of silt and sand grains coming into contact (dimensionless)

$U \quad=$ specific volume of a soil intra-aggregate matrix per unit mass of the oven-dried matrix itself; $U(w)$ is the auxiliary shrinkage curve $\left(\mathrm{cm}^{3} \mathrm{~g}^{-1}\right)$

$U_{\mathrm{a}} \quad=$ specific volume of soil aggregates per unit mass of oven-dried soil $\left(\mathrm{cm}^{3} \mathrm{~g}^{-1}\right)$

$U_{\text {ah }}=U_{\mathrm{a}}\left(w_{\mathrm{h}}{ }^{\prime}\right)$ value $\left(\mathrm{cm}^{3} \mathrm{~g}^{-1}\right)$

$U_{\mathrm{az}} \quad=$ oven-dried $U_{\mathrm{a}}$ value $\left(\mathrm{cm}^{3} \mathrm{~g}^{-1}\right)$

$U_{\mathrm{cp}} \quad=$ specific volume of clay pores in an intra-aggregate matrix per unit mass of the oven-dried matrix itself $\left(\mathrm{cm}^{3} \mathrm{~g}^{-1}\right)$

$U_{\mathrm{h}} \quad=U\left(w_{\mathrm{h}}\right)$ value $\left(\mathrm{cm}^{3} \mathrm{~g}^{-1}\right)$ 
$U_{\mathrm{i}}=$ contribution of an interface aggregate layer to $U_{\mathrm{a}}$ per unit mass of oven-dried soil $\left(\mathrm{cm}^{3} \mathrm{~g}^{-1}\right)$

$U_{\mathrm{lp}}=$ specific volume of lacunar pores in an intraaggregate matrix per unit mass of the oven-dried matrix itself $\left(\mathrm{cm}^{3} \mathrm{~g}^{-1}\right)$

$U_{\mathrm{lph}}=U_{\mathrm{lp}}\left(w_{\mathrm{h}}\right)$ value $\left(\mathrm{cm}^{3} \mathrm{~g}^{-1}\right)$

$U_{\mathrm{s}} \quad=$ specific volume of structural pores per unit mass of oven-dried soil $\left(\mathrm{cm}^{3} \mathrm{~g}^{-1}\right)$

$U_{\mathrm{z}} \quad=$ oven-dried $U$ value $\left(\mathrm{cm}^{3} \mathrm{~g}^{-1}\right)$

$U^{\prime} \quad=$ contribution of an intra-aggregate matrix to $U_{\mathrm{a}}$ and $Y$ per unit mass of oven-dried soil $\left(\mathrm{cm}^{3} \mathrm{~g}^{-1}\right)$

$U_{\mathrm{h}}{ }^{\prime} \quad=U^{\prime}\left(w_{\mathrm{h}}{ }^{\prime}\right)$ value $\left(\mathrm{cm}^{3} \mathrm{~g}^{-1}\right)$

$U_{\mathrm{z}}^{\prime} \quad=$ oven-dried $U^{\prime}$ value $\left(\mathrm{cm}^{3} \mathrm{~g}^{-1}\right)$

$V \quad=$ current value of the specific volume of a clay matrix $\left(\mathrm{cm}^{3} \mathrm{~g}^{-1}\right)$

$V_{\mathrm{cp}} \quad=$ specific volume of clay matrix pores $\left(\mathrm{cm}^{3} \mathrm{~g}^{-1}\right)$

$V_{\mathrm{z}} \quad=$ specific volume of a clay matrix in the oven-dried state $\left(\mathrm{cm}^{3} \mathrm{~g}^{-1}\right)$

$v_{\mathrm{s}} \quad=$ relative volume of clay solids (dimensionless)

$v_{\mathrm{z}} \quad=$ relative oven-dried clay volume (dimensionless)

$W \quad=$ total gravimetric water content per unit mass of oven-dried soil $\left(\mathrm{g} \mathrm{g}^{-1}\right)$

$W_{\mathrm{h}} \quad=W$ value at maximum aggregate (and soil) swelling or initial shrinkage point $\left(\mathrm{g} \mathrm{g}^{-1}\right)$

$W_{\mathrm{h}}{ }^{*}=W$ value that corresponds to possible filling of lacunar pores $\left(\mathrm{gg}^{-1}\right)$

$W_{\mathrm{m}} \quad=W$ value that corresponds to possible filling of structural pores $\left(\mathrm{g} \mathrm{g}^{-1}\right)$

$W_{\mathrm{m}}{ }^{*}=W$ value that corresponds to possible filling of lacunar and structural pores $\left(\mathrm{gg}^{-1}\right)$

$W_{\mathrm{n}} \quad=W$ value at the end point of the basic shrinkage area of a soil $\left(\mathrm{g} \mathrm{g}^{-1}\right)$

$W_{\mathrm{s}} \quad=W$ value at the end point of the structural shrinkage area of a soil $\left(\mathrm{g} \mathrm{g}^{-1}\right)$

$W_{\mathrm{z}} \quad=W$ value at the shrinkage limit of a soil $\left(\mathrm{g} \mathrm{g}^{-1}\right)$

$w \quad=$ gravimetric water content of an intra-aggregate matrix per unit mass of oven-dried intra-aggregate matrix itself $\left(\mathrm{g} \mathrm{g}^{-1}\right)$

$w_{\mathrm{h}}=w$ at the maximum swelling point of the intraaggregate matrix; $w_{\mathrm{h}}=W_{\mathrm{h}}\left(\mathrm{g} \mathrm{g}^{-1}\right)$

$w_{\mathrm{n}} \quad=w$ at the end point of the basic shrinkage of the intra-aggregate matrix $\left(\mathrm{g} \mathrm{g}^{-1}\right)$

$w_{z} \quad=w$ value at the shrinkage limit of the intra-aggregate matrix $\left(\mathrm{g} \mathrm{g}^{-1}\right)$

$w^{\prime}=$ contribution of an intra-aggregate matrix to the total water content $W$ per unit mass of oven-dried soil (g $\left.\mathrm{g}^{-1}\right)$

$w_{\mathrm{h}}{ }^{\prime}=w^{\prime}$ maximum at maximum aggregate swelling $W_{\mathrm{h}}$; $w_{\mathrm{h}}{ }^{\prime}<W_{\mathrm{h}}\left(\mathrm{g} \mathrm{g}^{-1}\right)$ $w_{\mathrm{n}}{ }^{\prime}=w^{\prime}$ at the end point of the basic shrinkage of the soil, $W_{\mathrm{n}} ; w_{\mathrm{n}}{ }^{\prime}=W_{\mathrm{n}}\left(\mathrm{g} \mathrm{g}^{-1}\right)$

$w_{\mathrm{s}}{ }^{\prime}=w^{\prime}$ at the end point of the structural shrinkage of the soil, $W_{\mathrm{s}} ; w_{\mathrm{s}}{ }^{\prime}=W_{\mathrm{s}}\left(\mathrm{g} \mathrm{g} \mathrm{g}^{-1}\right)$

$w_{\mathrm{z}}{ }^{\prime}=w^{\prime}$ value at the shrinkage limit of the soil, $W_{\mathrm{z}}$; $w_{\mathrm{z}}{ }^{\prime}=W_{\mathrm{z}}\left(\mathrm{g} \mathrm{g}^{-1}\right)$

$\bar{w} \quad=$ gravimetric water content of a clay matrix $\left(\mathrm{g} \mathrm{g}^{-1}\right)$

$\bar{w}_{\mathrm{h}},=\bar{w}$ values at maximum swelling, liquid limit,

$\bar{w}_{\mathrm{M}}, \quad$ air-entry point, and shrinkage limit, respectively

$\bar{w}_{\mathrm{n}}, \bar{w}_{\mathrm{z}}\left(\mathrm{g} \mathrm{g}^{-1}\right)$

$Y \quad=$ specific volume of a soil $\left(\mathrm{cm}^{3} \mathrm{~g}^{-1}\right)$

$Y_{\mathrm{z}} \quad=$ oven-dried $Y$ value $\left(\mathrm{cm}^{3} \mathrm{~g}^{-1}\right)$

$\Pi \quad=$ rigid clay porosity of an interface aggregate layer (dimensionless)

$\rho_{\mathrm{s}}, \rho_{\mathrm{w}}=$ density of solids and water $\left(\mathrm{g} \mathrm{cm}^{-3}\right)$

$\omega \quad=$ contribution of interface layer to $W$ per unit mass of oven-dried soil $\left(\mathrm{g} \mathrm{g}^{-1}\right)$

$\omega_{\mathrm{h}} \quad=\omega$ maximum at maximum aggregate swelling $W_{\mathrm{h}}(\mathrm{g}$ $\left.\mathrm{g}^{-1}\right)$

\section{REFERENCES}

[1] Reeve MJ, Hall DGM. Shrinkage in clayey subsoils of contrasting structure. J Soil Sci 1978; 29: 315-23.

[2] Braudeau E, Sene M, Mohtar RH. Hydrostructural characteristics of two African tropical soils. Eur J Soil Sci 2005; 56: 375-88.

[3] Tessier D, Pédro G. Recherches sur le rôledes minéraux argileux dans l'organisation et le comportement des sols. Livre Jubilaire du Cinquantenaire. AFES 1984; 223-34.

[4] Chertkov VY. The reference shrinkage curve at higher than critical soil clay content. Soil Sci Soc Am J 2007; 71(3): 641-55.

[5] Chertkov VY. The reference shrinkage curve of clay soil. Theor Appl Fracture Mech 2007; 48(1): 50-67.

[6] Chertkov VY. The soil reference shrinkage curve. Open Hydrol J 2007; 1: 1-18.

[7] Yule DF, Ritchie JT. Soil shrinkage relationships of Texas vertisols: I. Small cores. Soil Sci Soc Am J 1980; 44: 1285-91.

[8] Yule DF, Ritchie JT. Soil shrinkage relationships of Texas vertisols: II. Large cores. Soil Sci Soc Am J 1980; 44: 1291-5.

[9] McGarry D, Daniels IJ. Shrinkage curve indices to quantify cultivation effects of soil structure of a vertisol. Soil Sci Soc Am J 1987; 51: 1575-80.

[10] Crescimanno G, Provenzano G. Soil shrinkage characteristic curve in clay soils: Measurement and prediction. Soil Sci Soc Am J 1999; 63: 25-32.

[11] Braudeau E, Costantini JM, Bellier G, Colleuille H. New device and method for soil shrinkage curve measurement and characterization. Soil Sci Soc Am J 1999; 63: 525-35.

[12] Cabidoche Y-M, Ruy S. Field shrinkage curves of a swelling clay soil: analysis of multiple structural swelling and shrinkage phases in the prisms of a Vertisol. Aust J Soil Res 2001; 39: 143-60.

[13] Groenevelt PH, Bolt GH. Water retention in soil. Soil Sci 1972; 113(4): 238-45.

[14] Giraldez JV, Sposito G, Delgado C. A general soil volume change equation: I. The two-parameter model. Soil Sci Soc Am J 1983; 47: 419-22.

[15] Tariq A-R, Durnford DS. Analytical volume change model for swelling clay soils. Soil Sci Soc Am J 1993; 57: 1183-87.

[16] Olsen PA, Haugen LE. A new model of the shrinkage characteristic applied to some Norwegian soils. Geoderma 1998; 83: 67-81.

[17] Groenevelt PH, Grant CD. Re-evaluation of the structural properties of some British swelling soils. Eur J Soil Sci 2001; 52: 469-77. 
[18] Braudeau E, Frangi J-P, Mohtar RH. Characterizing nonrigid aggregated soil-water medium using its shrinkage curve. Soil Sci Soc Am J 2004; 68: 359-70.

[19] Peng X, Horn R. Modeling soil shrinkage curve across a wide range of soil types. Soil Sci Soc Am J 2005; 69: 584-92.

[20] Cornelis WM, Corluy J, Medina H, Hartmann R, Van Meirvenne M, Ruiz ME. A simplified parametric model to describe the magnitude and geometry of soil shrinkage. Eur J Soil Sci 2006; 57: 25868.

[21] Fiès JC, Bruand A. Particle packing and organization of the textural porosity in clay-silt-sand mixtures. Eur J Soil Sci 1998; 49: 557-67.

[22] Revil A, Cathles LM III. Permeability of shaly sands. Water Resour Res. 1999; 35(3): 651-662.

[23] Chertkov VY. Modeling the pore structure and shrinkage curve of soil clay matrix. Geoderma 2000; 95: 215-46.

[24] Chertkov VY. Modelling the shrinkage curve of soil clay pastes. Geoderma 2003; 112: 71-95.
[26] Chertkov VY. Intersecting-surfaces approach to soil structure. Int Agrophysics 2005; 19: 109-18.

[27] Chertkov VY. A physically based model for the water retention curve of clay pastes. J Hydrol 2004; 286: 203-26.

[28] Baer JU, Anderson SN. Landscape effects on desiccation cracking in an Aqualf. Soil Sci Soc Am J 1997; 61: 1497-502.

[29] Chertkov VY. Estimating the aggregate/intraaggregate mass ratio of a shrinking soil. Open Hydrol J 2008; 2: 7-14.

[30] Chertkov VY. Using the reference shrinkage curve to estimate the corrected crack volume of a soil layer. Open Mech J 2008; 2: 21 27.

[31] Chertkov VY. The geometry of soil crack networks. Open Hydrol J 2008; 2: 34-48.

Received: May 16, 2008

Revised: July 20, 2008

Accepted: July 31, 2008

(c) V.Y. Chertkov; Licensee Bentham Open.

This is an open access article licensed under the terms of the Creative Commons Attribution Non-Commercial License (http://creativecommons.org/licenses/by-nc/3.0/) which permits unrestricted, non-commercial use, distribution and reproduction in any medium, provided the work is properly cited. 